\title{
A method for studying antibiotic concentrations in inflammatory exudate
}

\author{
J. A. RAEBURN
}

From the University Department of Therapeutics, The Royal Infirmary, Edinburgh

SYNOPSIS A new technique is described for studying antibiotic concentrations in an experimental inflammatory exudate in vivo. In most exudates concentrations of four antistaphylococcal drugs which were of potential therapeutic significance could be assayed, and fucidin appeared to diffuse best. Higher concentrations of all antibiotics gained access to the lesion in the first two hours of inflammation, suggesting that their mobility did not depend on binding to cells during the inflammatory response. The technique may ultimately help to elucidate the relationship between antibiotics and host defences at the primary sites of infection.

Measurement of the antibiotic concentration achieved in a specific tissue after oral or parenteral drug administration is a guide to suitable therapy when that tissue is infected. However, acute inflammation may change some tissue antibiotic levels, for higher concentrations can be demonstrated in sputum which is purulent (May and Delves, 1965). Also it has been known for many years that, during the acute inflammatory stages of bacterial meningitis, more penicillin crosses the blood-brain barrier into the cerebrospinal fluid than in normal subjects (Rosenberg and Sylvester, 1944). Taken together, these findings suggest the possibility that some antibiotics pass into any inflamed area, aided by the acute inflammatory response (May, 1968). A possible mechanism can be argued from the studies in vitro of Saggers and Lawson (1970), who suggested that penicillin antibiotics enter the respiratory tract bound to leucocytes.

To investigate the concentration of antibiotics likely to occur in inflammatory exudates in vivo some modifications have been made to the 'skin window' technique originally described by Rebuck and Crowley (1955). This communication describes

Received for publication 7 January 1971. the method, which is suitable for comparing the kinetics of different antibiotics. The initial results with four antistaphylococcal drugs are summarized.

\section{Methods}

Healthy adult volunteers received antibiotic orally after a light meal and serial serum levels were assayed at half, one-and-a-half, two-and-a-half, and three-and-a-half hours. Just before the half-hour sample a small abrasion was made on the flexor aspect of the forearm using a high speed motor $(25,000 \mathrm{rpm})$ and a sterile buff as used by Senn, Holland, and Banerjee (1969). After skin preparation using methylated spirit the subject tensed the skin of the test area with his free hand. A few light touches with the rotating buff made the abrasion over an area of about $25 \mathrm{sq} \mathrm{mm}$. At half-an-hour after the antibiotic had been ingested a $12 \mathrm{~mm}$ diameter, sterile, weighed assay disc (Mast Laboratories Ltd) was applied to the abrasion and covered with a sterile glass slide which was firmly strapped in position. In the subsequent hour exudate was absorbed by the disc which, having been reweighed, was placed directly on a seeded assay plate. In all three discs were applied to the abrasion at hourly intervals so

\begin{tabular}{|c|c|c|c|c|c|}
\hline Antibiotic & Dose (mg) & Assay Organism & $\mathrm{p} H$ for Assay & $\begin{array}{l}\text { Incubation Temp- } \\
\text { erature }\left({ }^{\circ} \mathrm{C}\right)\end{array}$ & $\begin{array}{l}\text { Mean Peak Serum } \\
\text { Level }(\mathrm{mg} / \mathrm{ml})\end{array}$ \\
\hline $\begin{array}{l}\text { Cephalexin } \\
\text { Cloxacillin } \\
\text { Clindamycin } \\
\text { Fucidin }\end{array}$ & $\begin{array}{l}500 \\
500 \\
300 \\
500\end{array}$ & $\begin{array}{l}\text { Sarcina lutea } \\
\text { Sarcina lutea } \\
\text { Sarcina lutea } \\
\text { Corynebacteria xerosis }\end{array}$ & $\begin{array}{l}6 \cdot 5 \\
6 \cdot 5 \\
7 \cdot 4 \\
6 \cdot 0\end{array}$ & $\begin{array}{l}28 \\
37 \\
37 \\
37\end{array}$ & $\begin{array}{r}13 \cdot 8 \\
9 \cdot 0 \\
3 \cdot 75 \\
24 \cdot 4\end{array}$ \\
\hline
\end{tabular}

Table I Details of antibiotics studied 
that exudate antibiotic concentrations could be measured for the periods half to one-and-a-half hours, one-and-a-half to two-and-a-half hours, and two-and-a-half to three-and-a-half hours, with a serum level immediately before and after each exudate collection. All assays were carried out using the plate diffusion technique with the $12 \mathrm{~mm}$ assay discs as reservoirs for test or standard solutions. Subsequently two hours prediffusion time was allowed before overnight incubation. Table I summarizes details of the antibiotics studied including the dose given, the assay organism, and the average of the peak serum levels achieved.

\section{Results}

The serum levels obtained agreed with previous studies of each antibiotic (Braun, Tillotson, Wilcox, and Finland, 1968; McGhee, Smith, Wilcox, and Finland, 1968; Saggers, Harwood, and Day, 1968; Sutherland, Croydon, and Rolinson, 1970). The mean weight of exudate available for assay was $10.17 \mathrm{mg}$ with a range from $2.55 \mathrm{mg}$ to $24.97 \mathrm{mg}$. Figure 1 summarizes the information obtained in one individual after fucidin. On this occasion duplicate skin abrasions and exudate assays were performed, demonstrating the degree of reproducibility in one subject. Table II summarizes the results for all antibiotics by recording the means of each exudate level as a percentage of the average serum level during each collection. For cloxacillin experiments, the results are the mean of studies on only three subjects; the results for the other antibiotics were based on four experiments. There was considerable individual variation in the concentration of antibiotic assayed in the exudate and in part this

\begin{tabular}{|c|c|c|c|}
\hline \multirow[t]{2}{*}{ Antibiotic } & \multicolumn{3}{|c|}{ Time of Inflammation } \\
\hline & First Hour & Second Hour & Third Hour \\
\hline Fucidin & 42 & 46 & 28 \\
\hline Cephalexin & 38 & 19 & 20 \\
\hline Clindamycin & 34 & 9 & 4.9 \\
\hline Cloxacillin & 10 & 7 & 7 \\
\hline
\end{tabular}

Table II Mean of antibiotic concentration in skin exudates as a percentage of the average serum level

must reflect variations in lesion size. However, there was some evidence of individual factors operating since one subject consistently achieved higher levels iv in the exudate with all antibiotics than did his colleagues.

\section{Discussion}

The present study was parformed in an attempt to $\vec{O}$ investigate the relationship between antibiotic and $\stackrel{?}{0}$ leucocyte kinetics. Other workers have used the skin window technique to quantitate the cellular and protein changes during inflammation in differing

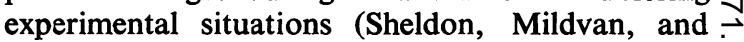
Allen, 1967; Fekety, 1969; Hutchins and Sheldon, 1970; Senn and Holland, 1970). Clearly, antibiotics can be studied in the same model and this provides an opportunity to compare their role with that of host defences.

It is of interest that the present studies show higher proportions of the serum concentration in exudate produced during the first two hours of the inflammatory response. This occurred with all four antistaphylococcal drugs studied. Other workers have shown that during the first two hours of inflamma-

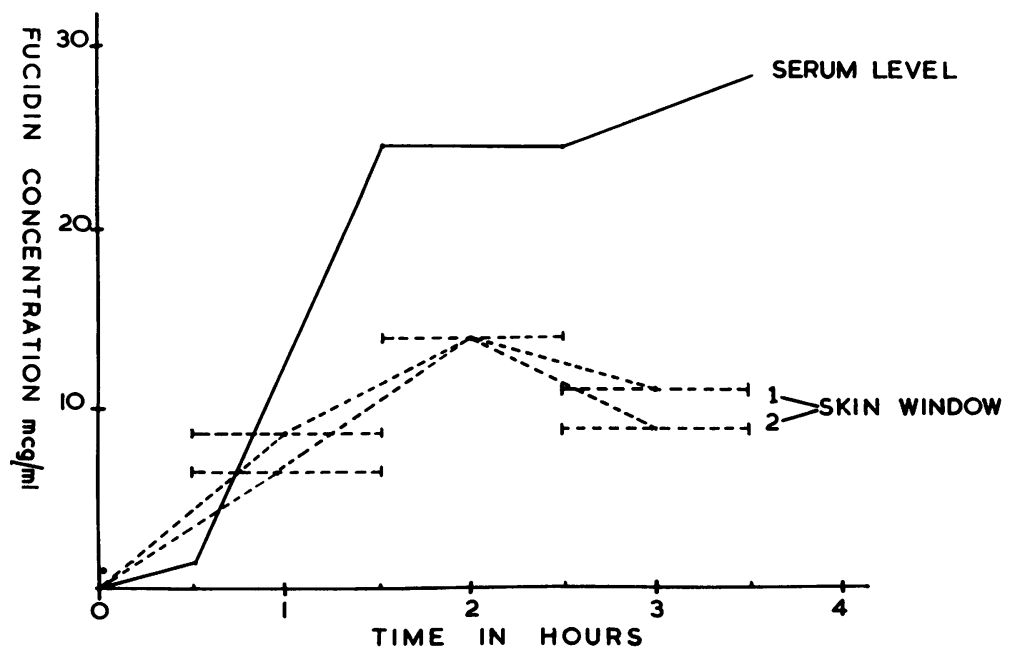

Fig. 1 Results in one individual after fucidin. 
tion, as reflected in skin window studies, cellular activity has not yet fully developed (Fekety, 1969; Kowal, 1969; Senn et al, 1969). Sheldon's experiments in rabbits (Sheldon et al, 1967) indicated higher proportions of albumin in exudate than in serum at the early stage of inflammation, at a time when antibiotic diffusion, as studied in this paper, seems more complete. However, he observed the first six hours of inflammation as one sample and did not separately measure albumin/globulin ratios in the first two hours. It is appreciated that the experimental method described in this paper may therefore tend to exaggerate exudate concentrations of antibiotics like fucidin which are highly albumin bound. However, other studies (Stewart, 1964) have also shown that fucidin achieves high concentrations in infected areas.

This technique presents several interesting possibilities for future studies of antibiotic kinetics. However, certain difficulties have not yet been overcome. First, each exudate level is based on only one diffusion test in contrast to serum assays (and standards) which were prepared in quadruplicate. Thus the accuracy of the exudate levels is compromised and may not bear close comparison with the serum results which are reproducible to within $15 \%$. Secondly, the varying weight of the exudate produced by different individuals makes it impossible to have truly comparable standards. The weight of serum absorbed on each disc for the standards was $35.64 \mathrm{mg}$ (SD $2.05 \mathrm{mg}$ ). Since all exudates weighed less than $25 \mathrm{mg}$ the results quoted here would underestimate the antibiotic concentrations in the exudate to a considerable extent. Clearly the methods must be improved in order to make valid comparisons between antibiotics.

This work was made possible by generous grants for technical assistance from Eli Lilly and Company Limited, and for equipment from Leo Laboratories Limited.
I would like to acknowledge my medical colleagues who were the subjects of these experiments and $\mathbf{M r}$ J. D. Devine and Miss E. J. Hanson for skilfully assisting in the assays. Above all, Professor R. H. Girdwood's continual advice and encouragement has been invaluable.

\section{References}

Braun, P., Tillotson, J. R., Wilcox, C., and Finland, M. (1968). Cephalexin and cephaloglycin activity in vitro and absorption and urinary excretion of single oral doses in normal young adults. Appl. Microbiol., 16, 1684-1694.

Fekety, F. R., Jr. (1969). Skin window studies of the effect of endotoxin upon the acute inflammatory response. Johns Hopk. med. J., 124, 291-295.

Hutchins, G. M., and Sheldon, W. H. (1970). Protein constituents in exudates of delayed hypersensitivity skin lesions. Arch. Path., 90, 377-382.

Kowal, E. (1969). Studies on the cellular composition of sterile skin exudate in proliferative diseases of the hemopoietic system. Pol. med. J., 8, 824-830.

McGhee, R. F., Jr., Smith, C. B., Wilcox, C., and Finland, M. (1968). Comparative studies of antibacterial activity in vitro and absorption and excretion of lincomycin and clinimycin. Amer. J. med. Sci., 256, 279-292.

May, J. R. (1968). The Chemotherapy of Chronic Bronchitis and Allied Disorders, p. 41. English University Press, London.

May, J. R., and Delves, D. M. (1965). Treatment of chronic bronchitis with ampicillin: some pharmacological observations. Lancet, 1, 929-933.

Rebuck, J. W., and Crowley, J. H. (1955). A method of studying leucocytic functions in vivo. Ann. N.Y. Acad. Sci., 59, 757-805.

Rosenberg, D. H., and Sylvester, J.C. (1944). The excretion of penicillin in the spinal fluid in meningitis. Science, 100, 132-133.

Saggers, B. A., Harwood, H. F., and Day, B. H. (1968). Serum levels with sodium fusidate. Brit. J. clin. Pract., 22, 429-430.

Saggers, B. A., and Lawson, D. (1970). The differential attachment of antibiotics to glycoprotein and blood lymphocytes. J. clin. Path., 23, 266-268.

Senn, H. J., and Holland, J. F. (1970). Funktionelle Beurteilung der Infekt abwehr bei Leukämie. Schweiz. med.Wschr., 100, 308-310.

Senn, H. J., Holland, J. F., and Banerjee, T. (1969). Kinetic and comparative studies on localised leukocyte mobilisation in normal man. J. Lab. Clin. Med., 74, 742-756.

Sheldon, W. H., Mildvan, D., and Allen, J. C. (1967). Some serum protein and cellular constituents of inflammatory lesions. Johns Hopk. med. J., 121, 113-133.

Stewart, G. T. (1964). Steroid antibiotics. Pharmakotherapia, 2, 137. Sutherland, R., Croydon, F. A. P., and Rolinson, G. N. (1970). Flucloxacillin, a new isoxazolyl penicillin, compared with oxacillin, cloxacillin and dicloxacillin. Brit. med.J., 4, 455-460. 